\title{
Laypersons' Psychological Barriers Against Rescue Actions in Emergency Situations - A Questionnaire Survey -
}

\author{
Haruka Shida; Chika Nishiyama, $\mathrm{PhD}$; Satoe Okabayashi, MD, PhD; \\ Yosuke Yamamoto, MD, PhD; Tomonari Shimamoto, PhD; \\ Takashi Kawamura, MD, PhD; Tetsuya Sakamoto, MD, PhD; Taku Iwami, MD, PhD
}

\begin{abstract}
Background: Although bystanders' performance is important to improve outcomes of patients after cardiac arrests, few studies have investigated the barriers of bystanders, including those who could not perform cardiopulmonary resuscitation or any other rescue actions in emergency situations. This study aimed to assess the relationship between the psychological barriers of laypersons who encountered emergency situations and their rescue actions.
\end{abstract}

Methods and Results: A questionnaire survey was conducted and this included laypersons who had encountered emergency situations during the last 5 years. Six questions were about the psychological barriers and 8 questions were about the laypersons' rescue actions. The primary outcome was any rescue actions performed by laypersons in an actual emergency situation. Overall, $7,827(92.8 \%)$ of 8,430 laypersons responded; of them, 1,361 (16.1\%) had encountered emergency situations during the last 5 years, and 1,220 (14.5\%) were eligible for inclusion in the analyses. Of the 6 psychological barriers, "fear of approaching a collapsed person" (adjusted odds ratio [AOR] 0.50; 95\% confidence interval [95\% $\mathrm{Cl}] 0.32-0.79$ ) and "difficulties in judging whether to perform any rescue action" (AOR 0.63; 95\% $\mathrm{Cl} 0.40-0.99$ ) were significantly associated with performing any rescue actions.

Conclusions: The fear of approaching a collapsed person and difficulties in judging whether to take any actions were identified as the psychological barriers in performing any rescue actions by laypersons who encountered emergency situations.

Key Words: Out-of-hospital cardiac arrest; Psychological barriers; Questionnaire survey; Rescue actions

$\mathbf{T}$ he number of emergency services dispatches in Japan was approximately 6.6 million in 2018 and is increasing annually. ${ }^{1}$ Laypersons encounter emergency situations. The incidence of out-of-hospital cardiac arrest (OHCA) of cardiac origin is approximately 70,000 annually in Japan; however, the rate of survival with favorable neurological outcomes is only $9.1 \% .^{1}$ Although early recognition, activation of the emergency response system, cardiopulmonary resuscitation (CPR), and defibrillation with an automated external defibrillator (AED) play key roles in saving the lives of patients who suffer from OHCA, bystander performance is not sufficient worldwide. ${ }^{2-5}$

CPR training is an effective method to improve confidence and willingness to perform CPR, and increase the rates of bystander CPR ${ }^{6-12} \mathrm{CPR}$ training is provided for laypersons throughout Japan mainly by municipal fire departments and the Japanese Red Cross Society. The number of people who are trained in CPR by fire departments is approximately 2 million in 1 year. In addition, many children are taught CPR at school, and Japanese people are required to take a CPR course when they obtain a driver's license. ${ }^{1,13,14} \mathrm{~A}$ previous study demonstrated that bystanders who had received CPR training performed CPR in emergency situations 3-fold more than those who had never received CPR training;"11 however, another study demonstrated that only $35 \%$ of bystanders performed CPR before the arrival of the emergency medical service personnel, even with previous CPR training. ${ }^{12}$

To better understand the positive and negative factors against bystander actions, studies evaluating an experience and performance in actual emergency situations are needed. ${ }^{15}$ Multiple factors have been reported as negative factors for

Received April 12, 2021; revised manuscript received September 19, 2021; accepted October 2, 2021; J-STAGE Advance Publication released online November 10, 2021 Time for primary review: 23 days

Department of Preventive Services (H.S.), Department of Healthcare Epidemiology (Y.Y.), School of Public Health in the Graduate School of Medicine, Kyoto University, Kyoto; Department of Critical Care Nursing, Kyoto University Graduate School of Human Health Science, Kyoto (C.N.); Kyoto University Health Service, Kyoto (S.O., T. Shimamoto, T.K., T.I.); and Department of Emergency Medicine, Teikyo University School of Medicine, Tokyo (T. Sakamoto), Japan

Mailing address: Chika Nishiyama, PhD, Department of Critical Care Nursing, Kyoto University Graduate School of Human Health Science, 53 Shogoin Kawahara-cho, Sakyo-ku, Kyoto 606-8507, Japan. E-mail: nishiyama.chika.3n@kyoto-u.ac.jp

All rights are reserved to the Japanese Circulation Society. For permissions, please e-mail: cj@j-circ.or.jp

ISSN-1346-9843 
bystanders to perform CPR, such as the sex of the collapsed person, the collapsed person's symptoms (e.g., vomiting and bleeding), residential location, confidence in CPR procedures, and difficulty in recognizing cardiac arrest. 12,16-20 Even if laypersons acquire the skills and knowledge of CPR by CPR training, they still have psychological barriers against performing CPR. ${ }^{10,12,21}$ Importantly, previous studies included only people who had encountered cardiac arrest or who had performed CPR; however, it has been reported that it is difficult for bystanders who encounter emergency situations to recognize whether the collapsed person is suffering from cardiac arrest or not. 19,22 $^{\text {Therefore, }}$ in order to encourage bystanders to perform any rescue actions in an emergency setting, it is essential to clarify the barriers they face, not only in cases of cardiac arrest, but also in cases of sudden collapse without cardiac arrest.

The aim of this study was to assess the relationship between the psychological barriers of laypersons who encountered emergency situations and their rescue actions.

\section{Methods}

\section{Study Design, Setting, and Population}

This cross-sectional study was performed in Japan between August 1, 2018 and November 20, 2018, and we conducted an anonymous self-administered paper-based questionnaire survey (Supplementary Appendix). This questionnaire survey was conducted among workers at a certain Japanese educational institution or company, or with trainees who participated in CPR training. These applicable CPR trainings were conducted by 4 fire departments, the Japanese Red Cross Society, and 3 other basic life support training organizations. Moreover, the questionnaires were conducted before the CPR training. These institutions agreed to cooperate in this research beforehand. We included adult laypersons (age $>18$ years), but excluded physicians, nurses, and paramedics.

\section{Questionnaire}

Questions About Psychological Barriers The questions about psychological barriers were formulated in 3 steps. First, based on a previous study, ${ }^{23}$ we created 5 provisional questions for each of the following 6 categories about psychological barriers: (1) fear of death; (2) pressure of taking responsibility for a life; (3) apprehension relating to problems after the CPR attempt; (4) difficulties in judging cardiac arrest; (5) concerns relating to CPR skills; and (6) confusion or anxiety.

Second, we used the modified Delphi method ${ }^{24}$ using a web-based questionnaire form twice with 10 experts of emergency medicine -4 physicians, 3 nurses, and 3 paramedics - in order to decide the tentative questions. The first round of the Delphi method asked the experts whether each provisional question expressed psychological barriers to some rescue actions by laypersons who encounter emergency situations, which was defined as encountering a collapsed person. A Likert scale was used by the experts to rate their thoughts about the tentative questions on a scale of 9 for "not extremely appropriate" and 1 for "extremely appropriate". We retained the provisional questions that received positive consensus, which was defined as a score of $\geq 6$ by $\geq 80 \%$ of the experts. We excluded the provisional questions that received negative consensus, which was defined as a score of $\leq 4$ by $\geq 80 \%$ of the experts. In the second round, we presented the results of the first round and asked the experts to reassess the remaining provisional questions the same way as had been done in the first round. Subsequently, we decided on the tentative questions after obtaining consensus from all the experts and researchers with expertise in the resuscitation field.

Finally, we asked 10 laypersons, including 5 persons who had encountered emergency situations before, to assess the tentative questionnaire in order to evaluate the face validity. Although 1 person did not respond to the invitation, 9 contributed to the final assessment. We presented the final questions about the psychological barriers under the following topics: (1) fear of approaching a collapsed person; (2) the situation that the collapsed person's life is dependent on one's own actions; (3) anxiety about the disadvantages to oneself; (4) difficulties in judging whether to take any rescue actions; (5) lack of confidence in performing any rescue actions correctly; and (6) confusion (panic) when facing a collapsed person. A 4-point rating scale was used to evaluate whether each psychological barrier had affected the laypersons' rescue actions on a scale of 4 for "strongly agree", 3 for "agree", 2 for "disagree" and 1 for "strongly disagree".

Questions About the Characteristics of Laypersons and Emergency Settings Based on previous studies, ${ }^{11,12,18}$ this questionnaire included 9 questions under the following 2 major topics associated with rescue actions: (1) layperson's characteristics, such as sex, age, previous experience of CPR training, and previous experience of performing any rescue actions; and (2) emergency settings, such as the location, relationship with the collapsed person, cause of collapse, sex of the collapsed person, and age category of the collapsed person.

Questions About Laypersons' Rescue Actions We formulated 8 questions that included the following topics to assess the laypersons' rescue actions in an actual emergency situation: (1) checking patient's consciousness; (2) gathering people or giving instructions to other laypersons; (3) making the emergency call; (4) looking for or carrying an AED; (5) chest compressions; (6) rescue breaths; (7) applying the AED pads and/or pushing the buttons of the AED; and (8) performing any resuscitation actions other than the above. The laypersons marked 1 of the following 3 choices: "Performed"; "Not performed"; and "Not performed because other people had already performed".

\section{Outcomes}

The primary outcome was any rescue action(s) performed, which was defined as the layperson having performed at least one of the following rescue actions: checking patient's consciousness, gathering people or giving instructions to other laypersons, making the emergency call, looking for the AED or carrying the AED, chest compressions, rescue breaths, applying the AED pads and/or pushing the buttons of the AED, and performing any rescue actions other than the above.

\section{Sample Size}

As we were not able to find any studies that assessed the proportion of performed any rescue actions, we projected the sample size in 2 stages as follows. First, the sample size was calculated based on the proportion of bystander CPR by the relationship with the collapsed person(s) according to previous studies. ${ }^{11,12} \mathrm{We}$ estimated the proportion of performing any rescue actions to a family member was $16.3 \%$, and that to other people was $34.2 \%$, and the ratio 


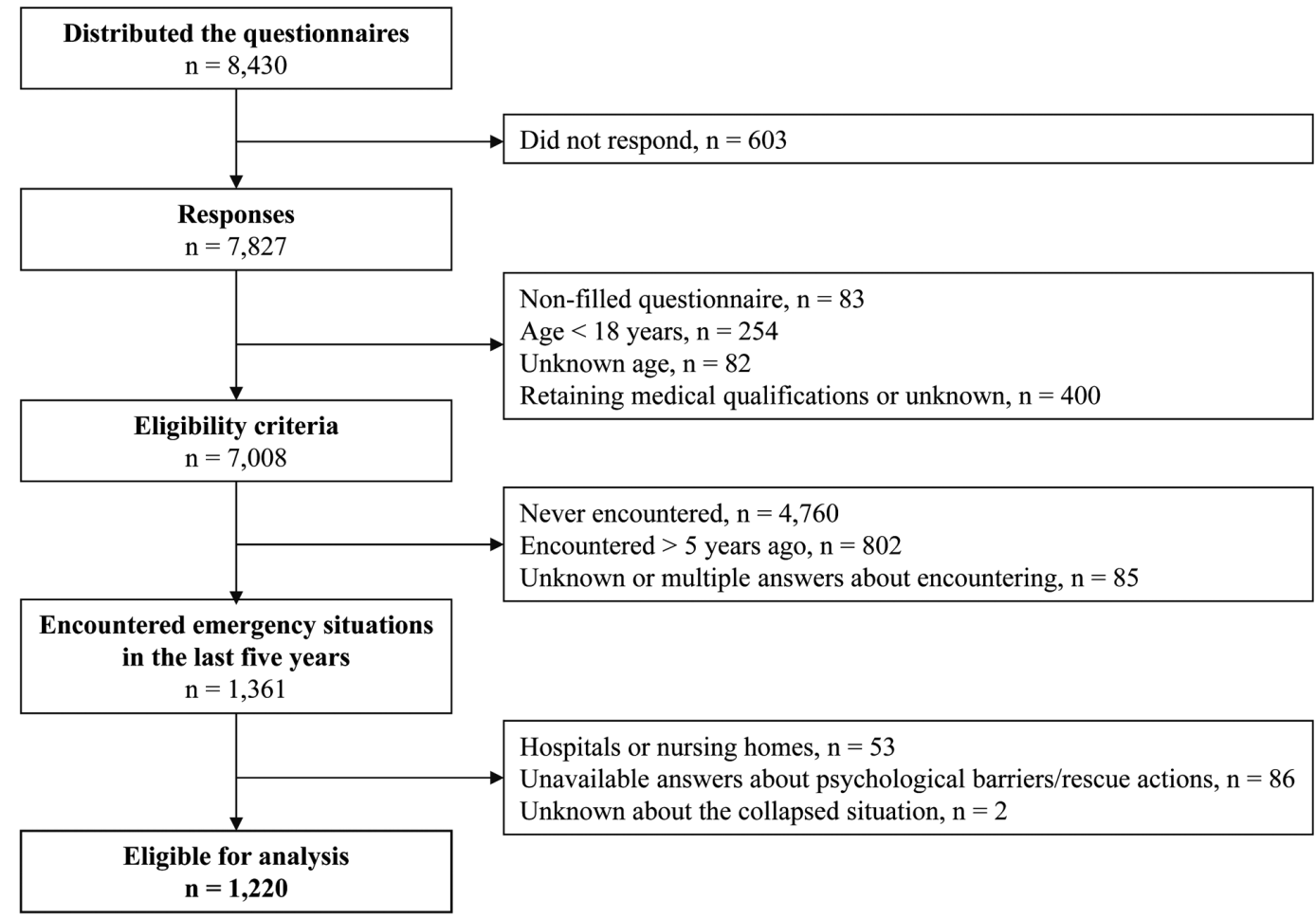

Figure 1. Flowchart showing the selection of respondents and analyses for this study.

Table 1. Characteristics of Laypersons

\section{Male sex}

Age, years, median (IQR)

Previous experience of CPR training

Previous experience of performing any rescue actions

Location of collapsed person

Workplace

Public area

Residence

Educational institution

Sports facility

Other locations

Relationship with the collapsed person

Family

Friend

Acquaintance

Colleague

Others

Cause of the collapse

Non-cardiac arrest

Cardiac arrest

Unknown

Collapsed person

Male

Adult

$$
\begin{gathered}
\text { Total }(\mathbf{n = 1 , 2 2 0}), \\
\mathbf{n}(\%) \\
646(53.0) \\
39(27-49) \\
744(61.0) \\
611(50.1) \\
\\
292(23.9) \\
177(14.5) \\
101(8.3) \\
79(6.5) \\
56(4.6) \\
489(40.1)
\end{gathered}
$$

$7(0.6)$

$104(8.5)$

$57(4.7)$

$54(4.4)$

$100(8.2)$

$898(73.6)$

$0(0.0)$

$868(71.1)$

$124(10.2)$

228 (18.7)

CPR, cardiopulmonary resuscitation; IQR, interquartile range. 


\begin{tabular}{|c|c|}
\hline & $\begin{array}{c}\text { Total }(n=1,220) \\
n(\%)\end{array}$ \\
\hline \multicolumn{2}{|l|}{ Checking patient's consciousness } \\
\hline Performed & $761(62.4)$ \\
\hline Not performed & $47(3.9)$ \\
\hline $\begin{array}{l}\text { Not performed because other people } \\
\text { had already performed this }\end{array}$ & $400(32.8)$ \\
\hline Missing & $12(0.9)$ \\
\hline \multicolumn{2}{|l|}{$\begin{array}{l}\text { Gathering people or giving instructions } \\
\text { to other laypersons }\end{array}$} \\
\hline Performed & $375(30.7)$ \\
\hline Not performed & $335(27.5)$ \\
\hline $\begin{array}{l}\text { Not performed because other people } \\
\text { had already performed this }\end{array}$ & $471(38.6)$ \\
\hline Missing & $39(3.2)$ \\
\hline \multicolumn{2}{|l|}{ Making the emergency call } \\
\hline Performed & $454(37.2)$ \\
\hline Not performed & $194(15.9)$ \\
\hline $\begin{array}{l}\text { Not performed because other people } \\
\text { had already performed this }\end{array}$ & $531(43.5)$ \\
\hline Missing & $41(3.4)$ \\
\hline \multicolumn{2}{|l|}{ Looking for or carrying an AED } \\
\hline Performed & $99(8.1)$ \\
\hline Not performed & $608(49.8)$ \\
\hline $\begin{array}{l}\text { Not performed because other people } \\
\text { had already performed this }\end{array}$ & $435(35.7)$ \\
\hline Missing & $78(6.4)$ \\
\hline \multicolumn{2}{|l|}{ Chest compressions } \\
\hline Performed & $80(6.6)$ \\
\hline Not performed & $753(61.7)$ \\
\hline $\begin{array}{l}\text { Not performed because other people } \\
\text { had already performed this }\end{array}$ & $331(27.1)$ \\
\hline Missing & $56(4.6)$ \\
\hline \multicolumn{2}{|l|}{ Rescue breaths } \\
\hline Performed & $25(2.0)$ \\
\hline Not performed & $820(67.2)$ \\
\hline $\begin{array}{l}\text { Not performed because other people } \\
\text { had already performed this }\end{array}$ & $311(25.5)$ \\
\hline Missing & $64(5.3)$ \\
\hline \multicolumn{2}{|l|}{$\begin{array}{l}\text { Applying the AED pads and/or pushing } \\
\text { the buttons of the AED }\end{array}$} \\
\hline Performed & $56(4.6)$ \\
\hline Not performed & $798(65.4)$ \\
\hline $\begin{array}{l}\text { Not performed because other people } \\
\text { had already performed this }\end{array}$ & $311(25.5)$ \\
\hline Missing & $55(4.5)$ \\
\hline \multicolumn{2}{|l|}{$\begin{array}{l}\text { Performing any rescue actions other } \\
\text { than the above }\end{array}$} \\
\hline Performed & $485(39.8)$ \\
\hline Not performed & $301(24.7)$ \\
\hline $\begin{array}{l}\text { Not performed because other people } \\
\text { had already performed this }\end{array}$ & $265(21.7)$ \\
\hline Missing & $169(13.9)$ \\
\hline
\end{tabular}

$A E D$, automated external defibrillator.

of the relationships with the collapsed person was $3: 7$ (family member: other people). Under the conditions of an $\alpha$ error of $5 \%$ and a power of $80 \%, 164$ family memberlaypersons and 71 other-laypersons were required.

Next, to reach the sample size $(n=235)$, we assumed that the proportion of encountering collapsed persons and the response rate of this questionnaire survey were $5 \%$ and $50 \%$, respectively. We estimated 9,600 questionnaires were needed to be distributed as follows. If the proportion of laypersons encountering cardiac arrests and performing CPR is $2 \%, 25$ the proportion that laypersons encounter cardiac arrests might be $4 \%$, because the proportion of bystanders performing CPR has been estimated to be $50 \% .^{1}$ In addition, we estimated the proportion of laypersons who encounter any emergency situations to be $5 \%$ because these situations are more common than that of cardiac arrest situations.

We planned to end the survey when the number of questionnaires answered by laypersons who encountered emergency situations achieved the sample size.

\section{Statistical Analysis}

We included laypersons who had encountered emergency situations during the 5 years before this study and excluded laypersons who encountered emergency situations at either hospitals or nursing homes.

Data were summarized as numbers and percentages for categorical variables and median and interquartile range for numerical variables. Furthermore, univariable and multivariable logistic regression analyses were applied to assess the associations between the psychological barriers of the laypersons and their rescue actions, and crude and adjusted odds ratios (AORs) with 95\% confidence intervals (CIs) were calculated.

The psychological barriers were divided into 2 categories on a scale of 1-4: scores of 1 or 2 (strongly agree and agree) were designated as "with barriers", and scores of 3 or 4 (disagree and strongly disagree) as "without barriers". Potential confounding factors (age, sex), factors that are considered associated with rescue actions, and each psychological barrier were included in multivariable analysis (location of the collapsed person [residence, workplace, educational institution, sports facility, public area, other locations including streets], cause of collapse [cardiac arrest, non-cardiac arrest, unknown], relationship with the collapsed person [others, family; friend, acquaintance, colleague], sex of the collapsed person [male, female], age category of the collapsed person [adult, child], previous experience of CPR training [yes, no], and previous experience of performing any rescue actions [yes, no]). All statistical analyses were performed using SPSS v24.0J (IBM Corp., Armonk, NY, USA).

\section{Ethical Considerations}

The study was conducted according to the Declaration of Helsinki and the Ethical Guidelines for Medical and Health Research Involving Human Subjects of Japan. Based on the guidelines, we provided all participants with a written explanation form, and if they agreed to cooperate in this survey, they answered the questionnaire. This study was approved by the Ethics Committees of the Kyoto University Graduate School of Medicine (R1393).

\section{Results}

\section{Respondents Included in the Analysis}

We distributed the questionnaires to 8,430 laypersons; $7,827(92.8 \%)$ responded and 7,008 $(83.1 \%)$ were eligible for this study criteria. Of those, 1,361 (16.1\%) laypersons had encountered emergency situations during the last 5 


\begin{tabular}{|c|c|c|c|c|c|c|c|c|c|c|}
\hline Fear of approaching a collapsed person & 10.7 & \multicolumn{2}{|l|}{23.4} & \multicolumn{3}{|c|}{24.0} & \multicolumn{3}{|c|}{41.6} & 0.2 \\
\hline $\begin{array}{l}\text { The situation that the collapsed person's life is } \\
\text { dependent on one's own actions }\end{array}$ & 9.6 & \multicolumn{2}{|l|}{22.0} & \multicolumn{3}{|c|}{25.7} & \multicolumn{3}{|c|}{41.8} & 0.9 \\
\hline Anxiety about the disadvantage to oneself & 11.9 & \multicolumn{4}{|c|}{26.9} & \multicolumn{4}{|c|}{54.8} & 1.2 \\
\hline $\begin{array}{l}\text { Difficulties in judging whether to take any rescue } \\
\text { actions }\end{array}$ & 12.4 & \multicolumn{2}{|c|}{23.9} & \multicolumn{3}{|c|}{23.4} & \multicolumn{3}{|c|}{39.3} & 1.1 \\
\hline $\begin{array}{l}\text { Lack of confidence in performing any rescue actions } \\
\text { correctly }\end{array}$ & 15.7 & \multicolumn{3}{|c|}{28.6} & \multicolumn{2}{|c|}{20.3} & \multicolumn{3}{|c|}{33.9} & 1.4 \\
\hline \multirow[t]{2}{*}{ Confusion (panic) when facing a collapsed person } & 9.3 & \multicolumn{2}{|l|}{21.1} & \multicolumn{3}{|c|}{28.9} & \multicolumn{3}{|c|}{39.6} & 1.1 \\
\hline & $10 \%$ & $20 \%$ & $30 \%$ & $40 \%$ & $50 \%$ & $60 \%$ & $70 \%$ & $80 \%$ & $90 \%$ & $100 \%$ \\
\hline 1 (Strongly agree) & gree) & agree) & & trongly & disagre & & issing & & & \\
\hline
\end{tabular}

Figure 2. Psychological barriers that affected the performance of any rescue actions by laypersons.

years and 1,220 (14.5\%) were eligible for analysis (Figure 1).

\section{Characteristics of the Laypersons}

The characteristics of the laypersons are summarized in Table 1. Of the 1,220 laypersons included in the analysis, $646(53.0 \%)$ were males and the median age was 39 years. The most frequent location of a collapsed person was workplaces $(23.9 \%)$, and the most frequent cause of collapse was non-cardiac arrest $(71.1 \%)$, followed by unknown $(18.7 \%)$, and cardiac arrest $(10.2 \%)$.

Performance of Any Rescue Actions in Emergency Settings Of the 1,220 laypersons, $915(75.0 \%)$ performed at least one of the rescue actions, of which $698(76.3 \%)$ performed multiple rescue actions. Of the rescue actions, the most frequent action performed was checking the consciousness of the collapsed person (761 [62.4\%]; Table 2).

\section{Psychological Barriers That Affected the Rescue Actions}

Figure 2 shows the degrees to which each psychological barrier had affected the performance of rescue actions by laypersons. The most frequent psychological barriers that laypersons ranked a score of 1 or 2 (strongly agree or agree, respectively) included "lack of confidence in performing any rescue actions correctly" (541 [44.3\%]), followed by "difficulties in judging whether to perform any rescue actions" (442 [36.3\%]), and "fear of approaching a collapsed person" (417 [34.1\%]). However, more than half the laypersons ranked a score of 3 or 4 (disagree or strongly disagree, respectively) for all psychological barriers.

\section{Associations Between the Psychological Barriers and Rescue Actions}

Table 3 summarizes the results of multivariable logistic regression analyses that were performed to assess the associations between the psychological barriers of the laypersons and their rescue actions. Among the 6 psychological barriers, "fear of approaching a collapsed person" (AOR $0.50 ; 95 \% \mathrm{CI} 0.32-0.79)$ and "difficulties in judging whether to perform any rescue actions" (AOR 0.63; 95\% CI 0.40 0.99 ) were significantly associated with the performance of any rescue actions. However, "the situation that the collapsed person's life is dependent on one's own actions", "anxiety about the disadvantages to oneself", "lack of confidence in performing any rescue actions correctly", and "confusion (panic) when facing a collapsed person" were not significantly associated with the performance of any rescue actions.

Among other factors, "previous experience of performing any rescue actions" was associated with the performance of any rescue actions, whereas "previous experience of CPR training" was not (Supplementary Table).

\section{Discussion}

We investigated the associations between the psychological barriers of laypersons who encountered emergency situations, including both cardiac arrest and non-cardiac arrest, and their rescue actions, irrespective of whether the laypersons performed any rescue actions. We observed that the psychological barriers of "fear of approaching a collapsed 
Table 3. Associations Between Laypersons' Psychological Barriers and Their Rescue Actions

\begin{tabular}{|c|c|c|c|}
\hline & $\mathrm{n} / \mathrm{N}(\%)$ & $\begin{array}{l}\text { Crude OR } \\
(95 \% \mathrm{Cl})\end{array}$ & $\begin{array}{l}\text { Adjusted OR } \\
\quad(95 \% \mathrm{Cl})\end{array}$ \\
\hline \multicolumn{4}{|l|}{ Psychological barriers } \\
\hline Fear of approaching a collapsed person & $257 / 417(61.6)$ & $0.35(0.27-0.46)$ & $0.50(0.32-0.79)$ \\
\hline $\begin{array}{l}\text { The situation that the collapsed person's life is dependent on } \\
\text { one's own actions }\end{array}$ & $252 / 386(65.3)$ & $0.48(0.36-0.62)$ & $0.99(0.62-1.59)$ \\
\hline Anxiety about the disadvantages to oneself & $134 / 208(64.4)$ & $0.52(0.38-0.72)$ & $1.26(0.77-2.06)$ \\
\hline Difficulties in judging whether to take any rescue actions & $277 / 442(62.7)$ & $0.35(0.27-0.46)$ & $0.63(0.40-0.99)$ \\
\hline Lack of confidence in performing any rescue actions correctly & $360 / 541(66.5)$ & $0.43(0.33-0.56)$ & $0.81(0.51-1.29)$ \\
\hline Confusion (panic) when facing a collapsed person & 252/371 (67.9) & $0.59(0.45-0.77)$ & $1.26(0.82-1.93)$ \\
\hline \multicolumn{4}{|l|}{ Other factors } \\
\hline Age of layperson & & $1.01(1.00-1.02)$ & $1.00(0.98-1.01)$ \\
\hline Sex of the layperson: Male & $502 / 646(77.7)$ & $1.35(1.04-1.75)$ & $1.25(0.89-1.75)$ \\
\hline \multicolumn{4}{|l|}{ Location of the collapsed person } \\
\hline Residence & $98 / 101(97.0)$ & Ref. & Ref. \\
\hline Workplace & 259/292 (88.7) & $0.24(0.07-0.80)$ & $0.20(0.06-0.71)$ \\
\hline Public area & $108 / 177(61.0)$ & $0.05(0.02-0.16)$ & $0.05(0.01-0.18)$ \\
\hline Educational institution & $52 / 79(65.8)$ & $0.06(0.02-0.20)$ & $0.04(0.01-0.14)$ \\
\hline Sports facility & $42 / 56(75.0)$ & $0.09(0.03-0.34)$ & $0.08(0.02-0.35)$ \\
\hline Other locations & $336 / 489(68.7)$ & $0.07(0.02-0.22)$ & $0.09(0.03-0.32)$ \\
\hline \multicolumn{4}{|l|}{ Cause of collapse } \\
\hline Non-cardiac arrest & $715 / 868(82.4)$ & Ref. & Ref. \\
\hline Cardiac arrest & 97/124 (78.2) & $0.77(0.49-1.22)$ & $0.56(0.31-1.00)$ \\
\hline Unknown & $103 / 228(45.2)$ & $0.18(0.13-0.24)$ & $0.25(0.17-0.36)$ \\
\hline Relationships with the collapsed person: Others & $640 / 898(71.3)$ & $0.42(0.30-0.60)$ & $0.86(0.55-1.35)$ \\
\hline Sex of the collapsed person: Female & $368 / 464(79.3)$ & $1.51(1.14-1.99)$ & $1.26(0.88-1.79)$ \\
\hline $\begin{array}{l}\text { Age category of the collapsed person: Child (approximately } \\
\leq 18 \text { years) }\end{array}$ & 101/122 (82.8) & $1.69(1.04-2.75)$ & $1.44(0.77-2.70)$ \\
\hline Previous experience of CPR training & $588 / 744(79.0)$ & $1.79(1.35-2.35)$ & $1.36(0.97-1.92)$ \\
\hline Previous experience of performing any rescue actions & $524 / 611(85.8)$ & $3.35(2.52-4.45)$ & $2.90(2.06-4.09)$ \\
\hline
\end{tabular}

$\mathrm{n}$ indicates the number of laypersons who performed any rescue actions; $\mathrm{N}$, Psychological barriers: the number of laypersons who felt psychological barriers; Other factors: the number of laypersons who selected each factor. Adjusted for each psychological barrier, age of the layperson, sex of the layperson, location of the collapsed person, cause of collapse, relationship with the collapsed person, sex of the collapsed person, age category of the collapsed person, previous experience of CPR training, previous experience of performing any rescue actions. Cl, confidence interval; CPR, cardiopulmonary resuscitation; OR, odds rations.

person" and "difficulties in judging whether to perform any rescue actions" were significantly associated with whether any rescue actions were performed. Although multiple studies have highlighted the psychological barriers using qualitative methods, ${ }^{12,19-21,26}$ the psychological barriers and the degree of their effects on the laypersons' rescue actions were unclear. The results of this study revealed the significant psychological barriers that should be emphasized.

Our results demonstrated that the barrier of "fear of approaching a collapsed person" was significantly associated with performing any rescue actions. Some studies have reported the presence of fear that laypersons feel in emergency situations and that they should be psychologically prepared to overcome this fear in emergency situations. ${ }^{26,27}$ Axelsson et al found that bystanders would like to know in advance the natural emotional reactions in emergency situations. ${ }^{19}$ Providing them with information about negative psychological reactions when encountering a collapsed person might be useful in reducing psychological barriers against performing any resuscitation actions. Moreover, it might be effective for laypersons to realistically imagine real emergency situations. For example, making good use of a role play and its debriefing during training, and explaining the bystander effect, which states that the presence of others discourages an individual from performing rescue actions in an emergency situation. ${ }^{28,29}$ In addition to teaching CPR skills and the pertinent knowledge, it is important to provide information about psychological barriers to encourage laypersons to overcome those barriers and perform rescue actions in an actual emergency situation. ${ }^{21,26}$

Although previous studies demonstrated the lack of confidence to perform CPR and panic as barriers, ${ }^{12,20,27}$ these barriers did not influence the performance of any rescue actions in this study. In contrast, following "fear of approaching a collapsed person", we found that "difficulties in judging whether to perform any rescue actions" was significantly associated with initiation of rescue actions. Laypersons who could not perform any rescue actions were the people who could not take the first step, such as talking to or approaching a collapsed person. These might be more essential barriers before they feel lack of confidence to perform CPR or confusion, and these barriers should be considered first to improve bystander performance. It is essential to emphasize that the conditions of a collapsed person do not worsen by any rescue actions that laypersons can perform, and that cardiac arrest is a condi- 
tion that can result in death within a short timeframe unless someone performs any rescue actions; in other words, it is better to do something rather than nothing. Moreover, in this study, the most frequent action performed was checking the patients' consciousness. It means this study can be interpreted as a study mainly evaluating the relationship between the rescue action of checking patient's consciousness and the psychological barrier to it. Following actions such as checking patient's consciousness, making the emergency call, and prompt initiation of chest compressions are also important to increase the rate of favorable neurological outcome in collapsed patients. However, because checking patient's consciousness should be the first action performed prior to other actions, assessing the relationship between the series of rescue actions, including checking patient's consciousness and the psychological barrier to them together, is meaningful even, if the checking patient's consciousness is the most frequent one. Further research related to the association between the psychological barrier and other rescue actions such as an emergency call and prompt chest compressions is needed.

Experience of CPR training has been shown to be a factor that prompted CPR in situations of cardiac arrest; ${ }^{11}$ however, this was not observed in this study. Although a current core curriculum element for basic life support training has been placed in knowledge and CPR skills acquisition, Axelsson et al reported that bystanders who had encountered a real situation of cardiac arrest asked for more practical CPR training. ${ }^{19}$ Therefore, incorporating bystander's psychological barriers associated with rescue actions into CPR training may improve bystander CPR. A better understanding of what laypersons feel in the actual emergency situation is warranted to provide more realistic CPR training.

In this study, $74.5 \%$ of laypersons performed at least 1 of the rescue actions, which was greater than a previous study that reported $48.6 \%$ of university students who encountered cardiac arrest performed any of the rescue actions. ${ }^{10}$ In our study, the questionnaires were mostly distributed at CPR training locations; therefore, laypersons who responded may have had higher motivation to perform any rescue actions. Furthermore, $>50 \%$ of laypersons in this study experienced previous CPR training and had previously performed rescue actions. These might have influenced the high proportion of participants performing any rescue actions.

This study has several limitations. The median age of this study population was 39 years, which might reflect adults who are working. In emergency situations in Japan, the majority of persons who collapse are elderly persons, and the location of collapse are their residences; ${ }^{1}$ therefore, the findings of this study may not apply in these situations. In addition, most of the respondents were participants of CPR training; therefore, this study population might have included laypersons who were interested in learning CPR, which might have influenced the results. Finally, rescue actions are recognized as socially desirable actions, ${ }^{27}$ therefore, social desirability bias may have influenced our results.

\section{Conclusions}

We demonstrated the associations between the psychological barriers faced by laypersons who encountered emergency situations and their rescue actions. The psychological barriers of "fear of approaching a collapsed person" and "difficulties in judging whether to perform any rescue actions" were significantly associated with not performing any rescue actions.

\section{Acknowledgments}

We are deeply grateful to all the people from the following institutions who cooperated with this study: the Japanese Red Cross Society, Osaka Municipal Fire Department, Takasaki District Fire Bureau, Sakai City Fire Bureau, Kishiwada City Fire Department, Osaka Life Support Association, Aichi PUSH, IBARAKI LifeSaving Education $\&$ AED PROJECT, Kyoto University, and The Dai-ichi Life Insurance Company, Limited. We are also deeply grateful to the following experts who contributed towards the Delphi method: Dr. Osamu Yamaoka, Dr. Junichi Izawa, Dr. Tasuku Matsuyama, Dr. Takeyuki Kiguchi, Mr. Keiji Akatsuka, Mr. Akira Tago, Mr. Shingo Moriguchi, Ms. Makiko Sano, Ms. Miyuki Inoko, and Ms. Izumi Chida, and the following laypersons who assessed the tentative questionnaire: Mr. Hiroshi Kiribuchi, Mr. Kazuhiro Takahashi, Mr. Hiroshi Yamaguchi, Ms. Yasuko Matsuoka, Mr. Toshio Maeshige, Ms. Nao Maeshige, Ms. Mari Aida, and Mr. Shinsuke Wada.

\section{Sources of Funding}

This work was supported by a Grant-in-Aid for Health, Labour and Welfare Sciences Research Grants (H29-Junkankitou-Ippan-009) from the Japanese Ministry of Health, Labour and Welfare. The funding organization has not contributed to the study design, collection, management, analysis, interpretation of data, writing of the report, or the decision to submit the report for publication.

All authors declare no conflicts of interest.

\section{IRB Information}

This study was approved by the Ethics Committees of the Kyoto University Graduate School of Medicine (R1393).

\section{Data Availability}

The deidentified participant data will not be shared.

\section{References}

1. Fire and Disaster Management Agency. Report on a study on social system development to improve survival from emergency cardiovascular disease [in Japanese]. https://www.fdma.go.jp/ publication/rescue/items/kkkg_r01_01_kyukyu.pdf; 2019 (accessed February 23, 2020).

2. Holmberg M, Holmberg S, Herlitz J. Effect of bystander cardiopulmonary resuscitation in out-of-hospital cardiac arrest patients in Sweden. Resuscitation 2000; 47: 59-70.

3. Kitamura T, Iwami T, Kawamura T, Nagao K, Tanaka H, Hiraide A; Implementation Working Group for the All-Japan Utstein Registry of the Fire and Disaster Management Agency. Nationwide public-access defibrillation in Japan. N Engl J Med 2010; 362: 994-1004.

4. Japan Resuscitation Council. 2015 Japanese guidelines for emergency care and cardiopulmonary resuscitation. Tokyo: IgakuShoin; 2016.

5. Kiguchi T, Okubo M, Nishiyama C, Maconochie I, Ong MEH, Kern KB, et al. Out-of-hospital cardiac arrest across the World: First report from the International Liaison Committee on Resuscitation (ILCOR). Resuscitation 2020; 152: 39-49.

6. Bhanji F, Finn JC, Lockey A, Monsieurs K, Frengley R, Iwami T, et al. Part 8: education, implementation, and teams: 2015 international consensus on cardiopulmonary resuscitation and emergency cardiovascular care science with treatment recommendations. Circulation 2015; 132: S242-S268.

7. Jiang $\mathrm{Y}, \mathrm{Wu} \mathrm{B}$, Long $\mathrm{L}$, Li J, Jin $\mathrm{X}$. Attitudes and willingness toward out-of-hospital cardiopulmonary resuscitation: A questionnaire study among the public trained online in China. $B M J$ Open 2020; 10: $\mathrm{e} 038712$.

8. Hamasu S, Morimoto T, Kuramoto N, Horiguchi M, Iwami T, Nishiyama C, et al. Effects of BLS training on factors associated with attitude toward CPR in college students. Resuscitation 2009; 80: $359-364$.

9. Kuramoto N, Morimoto T, Kubota Y, Maeda Y, Seki S, Takada 
$\mathrm{K}$, et al. Public perception of and willingness to perform bystander CPR in Japan. Resuscitation 2008; 79: 475-481.

10. Nishiyama C, Sato R, Baba M, Kuroki H, Kawamura T, Kiguchi $\mathrm{T}$, et al. Actual resuscitation actions after the training of chest compression-only CPR and AED use among new university students. Resuscitation 2019; 141: 63-68.

11. Tanigawa K, Iwami T, Nishiyama C, Nonogi H, Kawamura T. Are trained individuals more likely to perform bystander CPR? An observational study. Resuscitation 2011; 82: 523-528.

12. Swor R, Khan I, Domeier R, Honeycutt L, Chu K, Compton S. CPR training and CPR performance: Do CPR-trained bystanders perform CPR? Acad Emerg Med 2006; 13: 596-601.

13. Okubo M, Kiyohara K, Iwami T, Callaway CW, Kitamura T. Nationwide and regional trends in survival from out-of-hospital cardiac arrest in Japan: A 10-year cohort study from 2005 to 2014. Resuscitation 2017; 115: 120-128.

14. Mitamura H, Iwami T, Mitani Y, Takeda S, Takatsuki S. Aiming for zero deaths: prevention of sudden cardiac death in schools: Statement from the AED Committee of the Japanese Circulation Society. Circ J 2015; 79: 1398-1401.

15. Mancini ME, Soar J, Bhanji F, Billi JE, Dennett J, Finn J, et al. Part 12: Education, implementation, and teams: 2010 international consensus on cardiopulmonary resuscitation and emergency cardiovascular care science with treatment recommendations. Circulation 2010; 122: S539-S581.

16. Matsuyama T, Okubo M, Kiyohara K, Kiguchi T, Kobayashi $\mathrm{D}$, Nishiyama $\mathrm{C}$, et al. Sex-based disparities in receiving bystander cardiopulmonary resuscitation by location of cardiac arrest in Japan. Mayo Clin Proc 2019; 94: 577-587.

17. Blewer AL, McGovern SK, Schmicker RH, May S, Morrison LJ, Aufderheide TP, et al. Gender disparities among adult recipients of bystander cardiopulmonary resuscitation in the public. Circ Cardiovasc Qual Outcomes 2018; 11: e004710.

18. Langlais BT, Panczyk M, Sutter J, Fukushima H, Wu Z, Iwami $\mathrm{T}$, et al. Barriers to patient positioning for telephone cardiopulmonary resuscitation in out-of-hospital cardiac arrest. Resuscitation 2017; 115: $163-168$.

19. Axelsson A, Herlitz J, Ekström L, Holmberg S. Bystander-initiated cardiopulmonary resuscitation out-of-hospital: A first description of the bystanders and their experiences. Resuscitation 1996; 33: $3-11$.

20. Case R, Cartledge S, Siedenburg J, Smith K, Straney L,
Barger B, et al. Identifying barriers to the provision of bystander cardiopulmonary resuscitation (CPR) in high-risk regions: A qualitative review of emergency calls. Resuscitation 2018; 129: 43-47.

21. Malta Hansen C, Rosenkranz SM, Folke F, Zinckernagel L, Tjørnhøj-Thomsen T, Torp-Pedersen C, et al. Lay bystanders' perspectives on what facilitates cardiopulmonary resuscitation and use of automated external defibrillators in real cardiac arrests. J Am Heart Assoc 2017; 6: e004572.

22. Sayre MR, Koster RW, Botha M, Cave DM, Cudnik MT, Handley AJ, et al. Part 5: Adult basic life support: 2010 international consensus on cardiopulmonary resuscitation and emergency cardiovascular care science with treatment recommendations. Circulation 2010; 122: 298-324.

23. Shimamoto T, Nishiyama C, Ohura T, Kawamura T, Iwami T. Psychological conflicts in bystander cardiopulmonary resuscitation for out-of-hospital cardiac arrest. Int J First Aid Educ 2020; 3: 7-18.

24. McKenna HP. The Delphi technique: A worthwhile research approach for nursing? $J$ Adv Nurs 1994; 19: 1221-1225.

25. Sasaki M, Ishikawa H, Kiuchi T, Sakamoto T, Marukawa S. Factors affecting layperson confidence in performing resuscitation of out-of-hospital cardiac arrest patients in Japan. Acute Med Surg 2015; 2: 183-189.

26. Axelsson A, Herlitz J, Fridlund B. How bystanders perceive their cardiopulmonary resuscitation intervention; A qualitative study. Resuscitation 2000; 47: 71-81.

27. Riegel B, Mosesso VN, Birnbaum A, Bosken L, Evans LM, Feeny D, et al. Stress reactions and perceived difficulties of lay responders to a medical emergency. Resuscitation 2006; 70: 98-106.

28. Fischer P, Krueger JI, Greitemeyer T, Vogrincic C, Kastenmüller A, Frey D, et al. The bystander-effect: A meta-analytic review on bystander intervention in dangerous and non-dangerous emergencies. Psychol Bull 2011; 137: 517-537.

29. Stavert RR, Lott JP. The bystander effect in medical care. $N$ Engl $J$ Med 2013; 368: 8-9.

\section{Supplementary Files}

Please find supplementary file(s);

http://dx.doi.org/10.1253/circj.CJ-21-0341 